\title{
Prolonged diapause has sex-specific fertility and fitness costs
}

\author{
Aigi Margus $^{1}$ (D) $\cdot$ Leena Lindström ${ }^{1}$
}

Received: 27 August 2019 / Accepted: 30 November 2019 / Published online: 14 December 2019

(c) The Author(s) 2019

\begin{abstract}
Diapause in seasonal environments allows insects to survive adverse seasons. However, individuals can sometimes enter a prolonged diapause for more than a year, and also skip favourable seasons, which can bring additional costs through e.g. loss of metabolic resources. At the same time, prolonged diapause can be beneficial if it allows individuals to have a risk-spreading strategy to skip potentially suboptimal breeding seasons. We studied if prolonged diapause (2-year diapause) negatively affects the fertility and fitness of female and male Colorado potato beetles (Leptinotarsa decemlineata) compared to control (1-year diapause) beetles. We also tested the parental effects on the subsequent chemical stress tolerance of their offspring. We found that prolonged diapause carried fertility costs only for females who were less fertile than the control females. However, no differences in fertility were observed in males. Furthermore, prolonged diapause in females resulted in offspring with lower larvae-to-adult survival even though these offspring had accelerated development times. In contrast, paternal diapause duration had no effects on their offspring larvaeto adult survival, but prolonged diapause males sired offspring with slower development times than control males. Perhaps to compensate the costs related to prolonged diapause both older parents produced or sired offspring with higher body mass than control parents. Despite the differences in emergence mass, parental diapause duration did not affect offspring insecticide stress tolerance. The difference between females and males most likely results from the observed differences in prolonged diapause females' capacity to fight against cellular oxidative damage which was poorer compared to the control females. Even though prolonged diapause allows individuals to have a risk-spreading strategy it carries sex-specific fertility and fitness costs indicating that selection could favour this in males but not in females.
\end{abstract}

Keywords Diapause $\cdot$ Extended diapause $\cdot$ Fertility $\cdot$ Fitness $\cdot$ Insecticide $\cdot$ Invasive species $\cdot$ Prolonged diapause $\cdot$ Stress tolerance

Electronic supplementary material The online version of this article (https://doi.org/10.1007/s 1068 2-019-10024-1) contains supplementary material, which is available to authorized users.

Aigi Margus

aigi.margus@jyu.fi

1 Department of Biological and Environmental Science, University of Jyväskylä, P.O. Box 35, 40014 Jyväskylä, Finland 


\section{Introduction}

Diapause is an adaptation to cope with unfavourable conditions. Diapause, in insects, is a programmed arrest of growth, development, or reproduction, coupled with physiological changes to ensure the survival (Danks 1987; Tatar and Yin 2001). It can last one or more years depending on species and environmental conditions during the pre-diapause and different diapause stages (Tauber et al. 1986; Danks 2006). Prolonged diapause in many insect populations occurs when individuals stay in diapause for 12 , or more months and/or miss one or more breeding seasons. In extreme cases, diapause can surpass a decade. It is common among insects and up to $68 \%$ of individuals depending on the species can extend diapause for two or more years and most commonly for 2 years (Ushatinskaya 1984; Hanski 1988; Danks 1992; Menu and Debouzie 1993). Several studies have shown that prolonging diapause allows species to respond to the unpredictability of their habitat and thus increase the population stability (Menu and Debouzie 1993; Salman et al. 2016; Higaki 2016). Different diapause duration within a population could be viewed as a diversified bet-hedging or risk-spreading strategy (Menu and Debouzie 1993; Menu et al. 2000), which allows species to decrease the risk of reproductive failure during the unfavourable season. In addition, it could be a dispersal strategy as it has been shown to increase invasion speed in the stochastic environment (Mahdjoub and Menu 2008). In pest species variation in diapause duration could increase their resistance to crop rotation (Tauber and Tauber 2002). All these could be important for the invasive pest species in the colonization phase, where species are more likely to be exposed to environmental conditions they are poorly adapted to.

Prolonged diapause can also be costly for individuals, which can be seen as increased mortality (Sims 1983; Salman et al. 2019), and/or reduced performance (Matsuo 2006). Decreased survival could be due to longer exposure to chronic mortality factors, such as natural enemies and or due to depletion of energy reserves. Surviving long periods without eating is a challenge thus dormant insects have to build up energy reserves such as fat, glycogen and proteins (Arrese and Soulages 2010; Hahn and Denlinger 2011). As a result, diapausing individuals contain ca. 20-30\% fat when compared to non-diapausing beetles that contain only 5-10\% of fat (Danks 1987; Lehmann et al. 2012). Larger individuals commonly have greater energy reserves and thus have higher survival during diapause (Piiroinen et al. 2011) as well as higher post-diapause fertility (Hahn and Denlinger 2007). Thus, larger individuals have advantages for longer diapause (Matsuo 2006). On the other hand, longer diapause could also result in individuals with lower fat reserves and body weight (Ellers and Van Alphen 2002). Surprisingly, the fat reserves in the Colorado potato beetle are used so economically that they do not differ much between the winter diapause and prolonged diapause and are sufficient for reproduction after three winters (Ushatinskaya 1966). Prolonged diapause may also bring additional age effects, because there are many genes that are shared between diapause, ageing and longevity (Kučerová et al. 2016). Age effects could partly explain the often-observed increased mortality during prolonged diapause but this has not been studied.

Diapause duration does not only affect survival but is also correlated with other traits such as fertility and reproduction, moreover, it could also have transgenerational effects and affect the quality of their offspring (Chang et al. 1996; Wang et al. 2006). Many studies have been comparing non-diapausing individuals to diapausing individuals and have found that diapause has positive or no effect on female fecundity (Peferoen et al. 1981; Jansson et al. 1989). However, prolonged diapause leads to reduced dry 
weight, fat reserves, egg production and size (Kroon and Veenendaal 1998; Ellers and Van Alphen 2002). Less known is how prolonged diapause affects fertility and offspring production in males.

Besides quantity, individuals that enter prolonged diapause could also affect their offspring quality. For example, diapause has been associated with increased immune responses and stress resistance to extreme environmental conditions (Hahn and Denlinger 2007; Hand et al. 2016; Kučerová et al. 2016). During winter diapause, insects are exposed to low temperatures, while in prolonged diapause, insects also need protection against high summer temperatures and low humidity (Ushatinskaya 1966). A substantial proportion of genes affected by diapause is shared with the ones revealed in studies of aging and extended lifespan such as detoxification, stress-response pathways (i.e. stress resistance, metabolic resistance and genetic instability) as well as immune responses (Kučerová et al. 2016). As a contrast, if the increased lifespan is related to ageing, then prolonged diapause could also have a negative effect on offspring stress tolerance. Ageing has been associated with weakened stress tolerance, due to an increased homeostatic imbalance, which increases the risk of diseases associated with age (De Loof 2011). For example, it has been demonstrated that older wild Anopheles gambiae mosquitoes are more susceptible to permethrin insecticide exposure than younger mosquitoes (Chouaibou et al. 2012).

Here we examine the effects of prolonged diapause on the fertility (a number of eggs laid, hatching rate and the number of batches produced or sired) of both females and males and on the chemical stress tolerance of their offspring (i.e. survival) as well as development time and body mass. We used the Colorado potato beetle (Leptinotarsa decemlineata Say) as a study species due to its long-lasting diapause period (Tauber and Tauber 2002). We first investigated whether prolonged diapause reduces fertility. Previous studies that have compared non-diapausing adults to diapausing adults found positive or no effect on the total fecundity (Peferoen et al. 1981; Jansson et al. 1989). We hypothesize that if prolonged diapause brings additional costs it could also lead to reduced fertility. Second, we assessed whether the cost of prolonged diapause is higher in females than males. We expect the costs of prolonged diapause on fertility to be higher in females than males because the costs of producing sperm are lower than producing eggs. Third, we asked does the parental prolonged diapause increase the stress tolerance (i.e. survival) and/or affect the lifehistory traits (i.e. development time and adult body mass) of their offspring. Longevity in many species has been associated with increased stress tolerance because similar genetic mechanisms are suggested to be involved in both longevity and stress tolerance. Similarly, by skipping a breeding season, individuals can be exposed to unfavourable environmental conditions. Thus, if similar genetic or epigenetic mechanisms are involved in longevity and chemical stress tolerance we would expect increased stress tolerance in the offspring. On the other hand, physiological and reproductive performance decline with prolonged diapause could also result in lower offspring quality and thus decreased stress tolerance.

\section{Materials and methods}

\section{Study species}

The Colorado potato beetle (Leptinotarsa decemlineata Say; hereafter CPB) is an excellent species to study the effects of prolonged diapause because of its long-lasting diapause (Peferoen et al. 1981), which can last up to 9 years (Tauber and Tauber 2002). The beetle 
has a facultative diapause during their adult stage, which is induced by a short photoperiod and decreased temperature but also changes in food quality and decreases in the availability of food (de Wilde and Hsiao 1981; de Kort 1990; Yocum et al. 2011). Up to 25\% of the overwintering individuals can prolong their diapause for the second year (Alyokhin et al. 2013). This species breaks its diapause when temperatures rise above $10{ }^{\circ} \mathrm{C}$ (de Kort 1990). The beetle is mainly univoltine in the northern latitudes, but in case of multivoltine populations, there is always a proportion of first-generation adults entering diapause (Tauber et al. 1988; Tauber and Tauber 2002). The fact that adults from different generations form the next summer population can contribute to the maintenance of the genetic variability (Tauber et al. 1988).

\section{Laboratory conditions}

The Colorado potato beetles used in the current study originate from a laboratory colony established in 2010 from individuals collected from the fields in Vermont (USA; 44 $43^{\prime} \mathrm{N}$, $73^{\circ} 20^{\prime} \mathrm{E}$ ). Field collected beetles were mated in the laboratory and the next generation was overwintered individually in $100 \mathrm{ml}$ jars (containing $60 \mathrm{ml}$ of peat and a thin layer of plasticine to retain the moisture) in controlled climate cabinets (Type B3100; WeissTechnic, Reiskirchen-Lindenstruth, Germany) at $5{ }^{\circ} \mathrm{C}$, dark. Thereafter, in each spring adult beetles were mated at $23{ }^{\circ} \mathrm{C}$ under a long day photoperiod of $18 \mathrm{~h}$ light and $6 \mathrm{~h}$ dark to induce reproduction (de Kort 1990; Lehmann et al. 2012). Pairs were kept on taped Petri dishes ( $9 \mathrm{~cm}$ ). Eggs were collected from these matings and hatching was recorded daily. Hatched larvae were grown in small family groups in plastic containers $(0.51)$ and fed daily with fresh leaves and stems of potato (Solanum tuberosum L. var. Challenger). Newly emerged adults were grown under short day photoperiod of $12 \mathrm{~h}$ light and $12 \mathrm{~h}$ dark and were allowed to gather reserves to enter diapause (de Kort 1990; Lehmann et al. 2012). Beetles generally burrow for diapause 10-15 days after adult eclosion (Piiroinen et al. 2011). Overwintering was initiated by gradually decreasing temperatures from 23 to $20^{\circ} \mathrm{C}, 15^{\circ} \mathrm{C}$, $10{ }^{\circ} \mathrm{C}$, and finally at $5{ }^{\circ} \mathrm{C}$, with two-week intervals. The summer conditions were initiated similarly by gradually increasing the temperatures. The '2-year-diapause' beetles did not break their diapause at $15{ }^{\circ} \mathrm{C}$. Thus, they were kept at $15^{\circ} \mathrm{C}$ for the summer, after which they were moved to $10{ }^{\circ} \mathrm{C}$, and overwintered at $5{ }^{\circ} \mathrm{C}$ for the second winter together with the '1-year-diapause' beetles. In total, the 2-year-diapause beetles stayed in diapause for 22-23 months and the 1-year-diapause beetles for 9-10 months. For long it was believed that diapausing beetles do not usually survive for more than 1 year under laboratory conditions (Peferoen et al. 1981).

Before the actual experiment, we tested the physiological conditions from another set of individuals not used in the experiment. For that, we compared the oxidative status biomarkers between the 2-year-diapause females and males and the 1-year-diapause young females and males. Oxidative status biomarkers: catalase (CAT), glutathione peroxidase (GPx), the ratio of reduced to oxidized glutathione (GSH/GSSG), glutathione-S-transferase (GST), superoxide dismutase (SOD), total glutathione (tGSH), and glutathione reductase (GR) were measured according to Margus et al. (2019) and Rainio et al. (2019). Lipid hydroperoxides was measured according to Vuori et al. (2015) with modifications by Rainio et al. (2019) (Suppl. mat.). Prolonged diapause in females leads to higher principal component (GSH/GSSG $\downarrow$, GST $\uparrow$ ) scores suggesting that prolonged diapause leads to decreases GSH/GSSG and increases GST activities (Suppl. mat.; S1). We identified a similar trend in males $(p=0.094$; Supp. Table S1), meaning that the diapause duration 
decreases GSH/GSSG activity and increases GST activity. However, our dataset was likely too small to detect significant differences in males. GSH is the major intracellular nonprotein defence against free radical (Collatz and Sohal 1986; Krishnan et al. 2009), thus decreased GSH/GSSG ratio could mean decreased defence against free radicals. This could lead to increased cellular oxidative stress and DNA damage (Asensi et al. 1999). Increased GST activity has been associated with higher insecticide resistance (Enayati et al. 2005).

\section{Experimental setup}

To investigate the effect of prolonged diapause on females, fourteen 1-year-diapause females (6th generation, born 2014) and fourteen 2-year-diapause females (5th generation, born 2013) were paired with 1-year-diapause males (6th generation) in summer 2015. Before mating the females with males, we measured the body mass of all the females. We assessed that the 2-year-diapause females had similar body mass as the 1-year-diapause females (independent sample $t$ test: $\mathrm{t}_{1,26}=0.004, p=0.997$ ). Each male was mated with one female from both diapause groups to rule out the paternal effects from the maternal effects. Males were randomly swapped between the females in every third day. The observed mating success was $100 \%$. However, egg-laying success was higher for 1-year-diapause females $(=100 \%)$ and lower for 2-year-diapause females $(=86 \%)$.

Paternal diapause experiment was conducted similarly as the maternal age experiment. Males from both diapause groups 1-year-diapause (6th generation, born 2014) and 2-year-diapause (5th generation, born 2013) males were mated with two 1-year-diapause females, to ensure mating success. In total 12 males from both diapause groups were each mated with two 1-year-diapause females. Before mating the males with the female, males we measured the body mass of all the males. We found that the 2-year-diapause males had similar body mass as the 1 -year-diapause males (independent sample $t$-test: $t_{1,22}=1.7$; $p=0.102$ ). Males were swapped randomly between females in every third day. Both mating and egg-laying success were $100 \%$ in both male diapause groups, suggesting the males from both diapause groups were equally successful in mating with the females and that all the females laid eggs.

Mated beetles from both maternal and paternal experiment were fed daily with leaves and stems of fresh potato. Eggs were collected, counted and checked for hatching daily. Total hatching was estimated from a number of larvae that had hatched by the second day (i.e. based on 1-day-old larvae). Thereafter, hatched larvae were fed with fresh potato leaves daily, until the second instar.

\section{Insecticide exposure experiment}

To test whether parental diapause duration affects stress tolerance we exposed their offspring to insecticide. Second instar larvae (4-6 days old; based on the size of the head capsule $1.03+0.09 \mathrm{~mm}$ ) (Boiteau and Le Blanc 1992) were divided from each family into two different treatment groups: insecticide and control. In the insecticide stress exposure group, $3 \mu \mathrm{l}(123 \mu \mathrm{g} / \mathrm{ml})$ of azinphos-methyl (AZ, PESTANAL, Sigma-Aldrich, USA) was applied topically to the dorsal abdominal segment. In the control group, $3 \mu \mathrm{l}$ of acetone was used instead. Two hours after the insecticide treatment the survival was recorded, and a fresh potato leaflet was supplied to the viable larvae. After $24 \mathrm{~h}$ larvae were transferred into the new Petri dishes and fed daily. At the end of the fourth instar, larvae were transferred into plastic boxes containing soil to allow them to pupate. 
Soil boxes were checked daily for adult emergence. Newly emerged adults were sexed (female/male) and weighted (mg; Mettler AM100, Toledo). Survival after $24 \mathrm{~h}$ (dead/ alive), larvae-to-adult survival (dead/alive), adult emergence body mass (mg) were recorded and development time (days; from egg hatching date until adult emergence date) was calculated.

\section{Statistical analysis}

Statistical analyses were computed with IBM SPSS Statistics 22 (New York, USA) and both maternal and paternal diapause duration effects were analysed similarly. Principal component analyses (PCA) were performed to investigate the diapause duration effects on female and male fertility (i.e. total number of egg batches laid, total number of eggs laid and total number of eggs hatched within 10 days since mating). We used PCA to reduce the number of dimensions for further analysis. PCA sampling adequacy was tested with Kaiser-Meyer-Olkin test with Promax rotation $(\mathrm{KMO}=0.642$, Approx $\left.\chi^{2}=81.8, d f=3, p<0.001\right)$. The PCA for female fertility resulted in a principal component (PC1; total number of eggs $\uparrow$, total number of batches $\uparrow$, and total number of hatching larvae $\uparrow$ within the 10 days since mating) explaining $83 \%$ of the variance (Eigenvalue 2.5). This PC was used in the further analysis with ANOVA, where we investigated the main effects of maternal diapause duration on the reproduction. Maternal diapause duration was set as a fixed factor and male ID as a random factor. The PCA sampling adequacy for male fertility was also tested with KMO-test with a Pro$\max$ rotation $\left(\mathrm{KMO}=0.611\right.$, Approx. $\left.\chi^{2}=76.8, d f=3, p<0.001\right)$. The PCA for male fertility resulted in a PC (PC1; total number of batches $\uparrow$, total number of eggs $\uparrow$, total number of hatched larvae $\uparrow$ within 10 days since mating) explaining $78 \%$ of the variance (Eigenvalue 2.3). These PC values were used in further analysis with ANOVA, where we investigated the effects of paternal diapause duration on reproduction. Paternal diapause duration was set as a fixed factor.

Larval survival after $24 \mathrm{~h}$ of the insecticide exposure and larvae-to-adult survival were analysed with generalized linear models using GLM binomial distribution with a logit link function. The number of surviving individuals was set as dependent variable and the number of treated individuals as a number of events. Maternal or paternal diapause duration and insecticide exposure treatment (control/insecticide stress) were entered as fixed factors. Interactions were included.

Development time (days; from egg hatching date until adult emergence date) and emergence body mass (mg) of the offspring were analysed with ANOVA. Maternal or parental diapause duration and insecticide exposure were entered as fixed factors. Nonsignificant interactions were omitted from the final models. Offspring sex was included as a fixed factor in development time analysis. However, the effects of parental diapause duration on body mass were analysed separately for female and male offspring. Normality was checked with Kolmogorov-Smirnov and Shapiro-Wilk test and homogeneity with Levene's test to meet the assumptions of ANOVA.

We excluded 4 individuals when calculating development times in the paternal experiment due to missing data. We excluded six individuals out of $613(0.98 \%)$ from the maternal diapause experiment (2-year-diapause: 1 -year-diapause $=3: 3$ ), and eleven individuals out of $1129(0.97 \%)$ from paternal diapause experiment (2-year-diapause:1year-diapause $=5: 6$ ) from the body mass analysis due to forewing deformations. 


\section{Results}

\section{Does prolonged diapause affect fertility in females and males?}

The PC1 (total number of eggs $\uparrow$, a total number of batches $\uparrow$, a total number of hatched larvae $\uparrow$ within 10 days since mating) of female fertility was affected by the maternal diapause duration $\left(\mathrm{F}_{1,14}=6.9, p=0.021\right)$ but not by the paternal ID $\left(\mathrm{F}_{1,14}=1.2, p=0.362\right)$. Females that had diapaused for 1 year had higher fertility (mean $\mathrm{PC} 1=0.55 \pm 0.23$ s.e.) than females that had prolonged their diapause for two years (mean $\mathrm{PC} 1=-0.32 \pm 0.23$ s.e.) (Fig. 1a-c). The PC1 (number of eggs $\uparrow$, number of batches $\uparrow$, number of hatched larvae $\uparrow$ within 10 days since mating) of male fertility was not affected by the diapause duration $\left(\mathrm{F}_{1,46}=0.04\right.$, $p=0.846)$ (Fig. 2a-c).

\section{Does parental prolonged diapause affect offspring survival?}

Offspring survival after $24 \mathrm{~h}$ of the insecticide treatment was decreased by the insecticide exposure but was not affected by the maternal diapause duration, or their interaction (Tables 1,2). This suggests that the maternal diapause duration does not increase or decrease the sensitivity to insecticide exposure. It can be seen from Table 2, that the survival after $24 \mathrm{~h}$ was the highest among the offspring in the control treatment groups and lowest among the offspring in the insecticide stress group. Maternal diapause duration affected larvae-to-adult survival, suggesting that 2-year-diapause mothers produced poorer offspring (Tables 1,2). As shown in Table 2, larvae descending from the 2-year-diapause mothers were $6 \%$ less likely to reach the adult stage when compared to larvae descending from the 1-year-diapause mothers. Insecticide exposure had no effect on the overall larvaeto-adult survival (Table 1).

Offspring survival after $24 \mathrm{~h}$ of the insecticide treatment was decreased by the insecticide exposure but was not affected by the paternal diapause duration or their interaction (Tables 1, 2). Survival after $24 \mathrm{~h}$ was the highest among the offspring from the
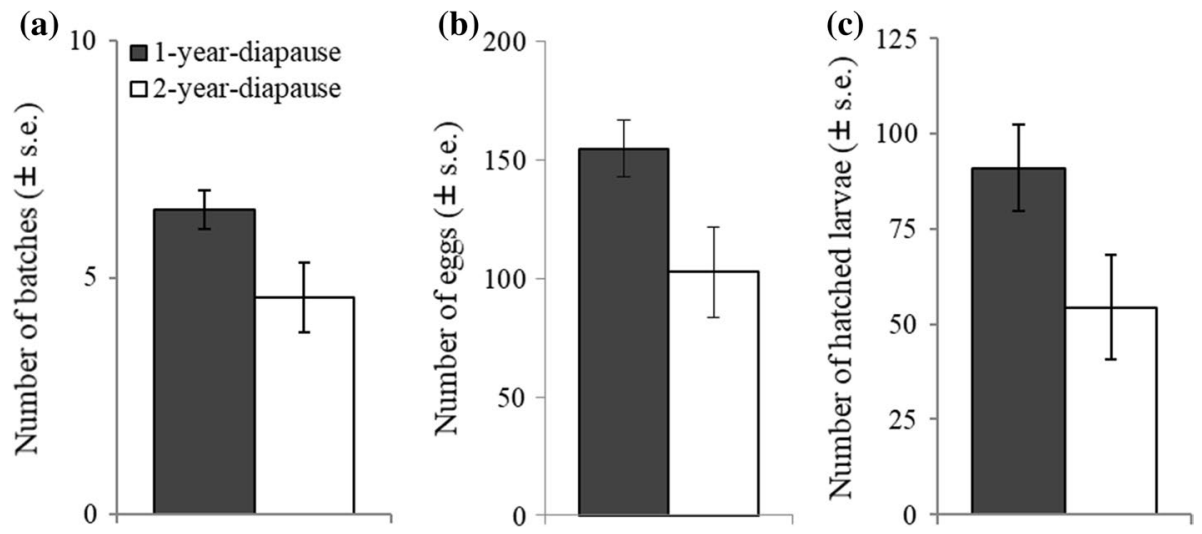

Fig. 1 Maternal diapause duration (2-year-diapause/1-year-diapause) effects on fertility a number of egg batches $( \pm$ s.e. $)$, b number of eggs ( \pm s.e.), and $\mathbf{c}$ number of hatched larvae $( \pm$ s.e.) within the 10 days since mating 

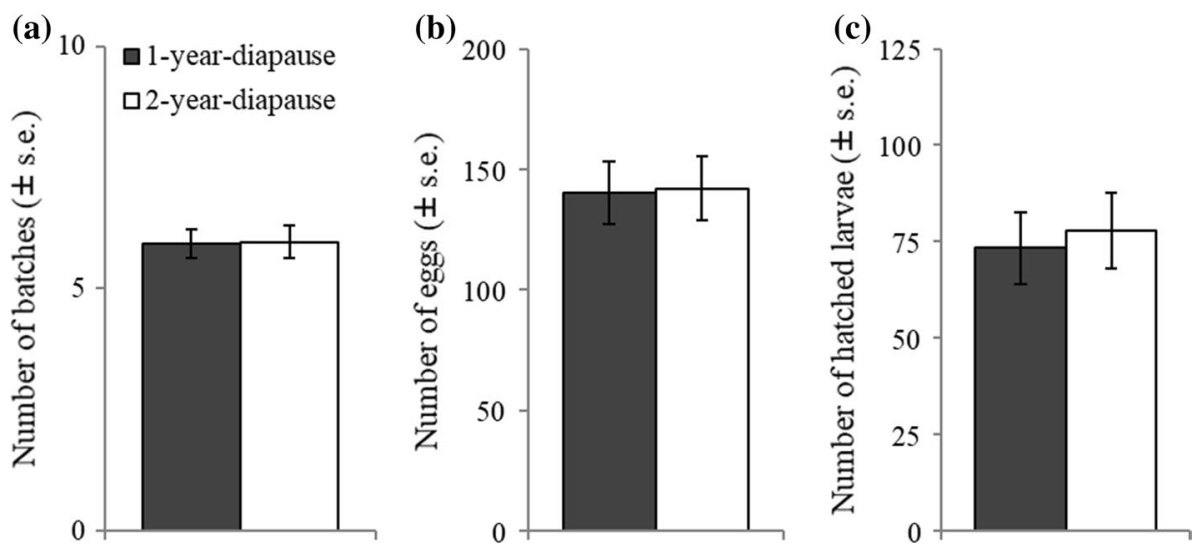

Fig. 2 Paternal diapause duration (2-year-diapause/1-year-diapause) effects on fertility a number of egg batches ( \pm s.e.), b number of eggs ( \pm s.e.), and $\mathbf{c}$ number of hatched larvae $( \pm$ s.e.) within the 10 days since mating

Table 1 Binary logistic regression analysis for larval $24 \mathrm{~h}$ and larvae-to-adult survival in relation to maternal or paternal diapause duration and insecticide stress treatment. Significant results are marked in bold

\begin{tabular}{|c|c|c|c|c|c|}
\hline & Survival & Source & Wald Chi square & $d f$ & $p$ \\
\hline \multirow[t]{8}{*}{ Maternal } & \multirow[t]{4}{*}{ After $24 \mathrm{~h}$} & (Intercept) & 149.1 & 1 & $<0.001$ \\
\hline & & Diapause duration & 1.3 & 1 & 0.254 \\
\hline & & Insecticide stress & 25.9 & 1 & $<0.001$ \\
\hline & & $\begin{array}{l}\text { Diapause duration } \times \text { insecticide } \\
\text { stress }\end{array}$ & 0.2 & 1 & 0.689 \\
\hline & \multirow[t]{4}{*}{ Larvae-to adult } & (Intercept) & 7.3 & 1 & 0.007 \\
\hline & & Diapause duration & 4.3 & 1 & 0.037 \\
\hline & & Insecticide stress & 0.6 & 1 & 0.434 \\
\hline & & $\begin{array}{l}\text { Diapause duration } \times \text { insecticide } \\
\text { stress }\end{array}$ & 0.5 & 1 & 0.464 \\
\hline \multirow[t]{8}{*}{ Paternal } & \multirow[t]{4}{*}{ After $24 \mathrm{~h}$} & (Intercept) & 199.2 & 1 & $<0.001$ \\
\hline & & Diapause duration & 1.3 & 1 & 0.250 \\
\hline & & Insecticide stress & 31.9 & 1 & $<0.001$ \\
\hline & & $\begin{array}{l}\text { Diapause duration } \times \text { insecticide } \\
\text { stress }\end{array}$ & 1.6 & 1 & 0.201 \\
\hline & \multirow[t]{4}{*}{ Larvae-to-adult } & (Intercept) & $<0.01$ & 1 & 0.953 \\
\hline & & Diapause duration & 0.7 & 1 & 0.394 \\
\hline & & Insecticide stress & 7.9 & 1 & 0.005 \\
\hline & & $\begin{array}{l}\text { Diapause duration } \times \text { insecticide } \\
\text { stress }\end{array}$ & 2.1 & 1 & 0.151 \\
\hline
\end{tabular}

Significant results are marked in bold

control group and lowest in the insecticide exposure group (Table 2). Larvae-to-adult survival was not affected by the paternal diapause duration but by the insecticide 
Table 2 Estimated marginal means for the maternal and paternal diapause duration (1-year-diapause/2year-diapause) and insecticide treatment (insecticide stress/control) on the survival after $24 \mathrm{~h}$ of the insecticide exposure and larvae-to-adult survival

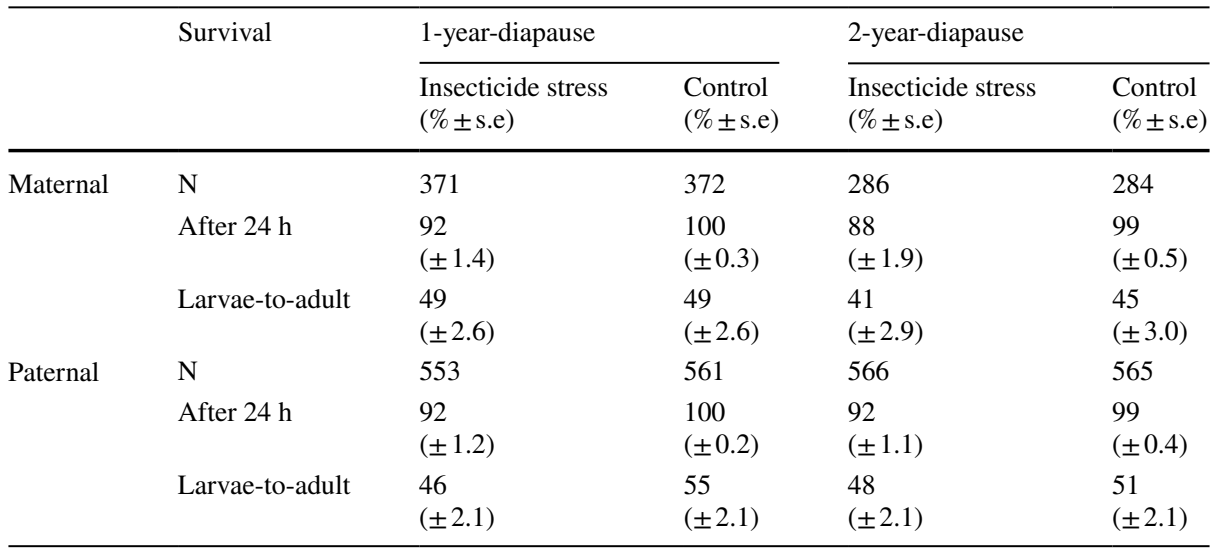

exposure (Table 2). As shown in Table 2, larvae descending from the control group were more likely to reach the adult stage when compared to larvae from the insecticide exposure group.
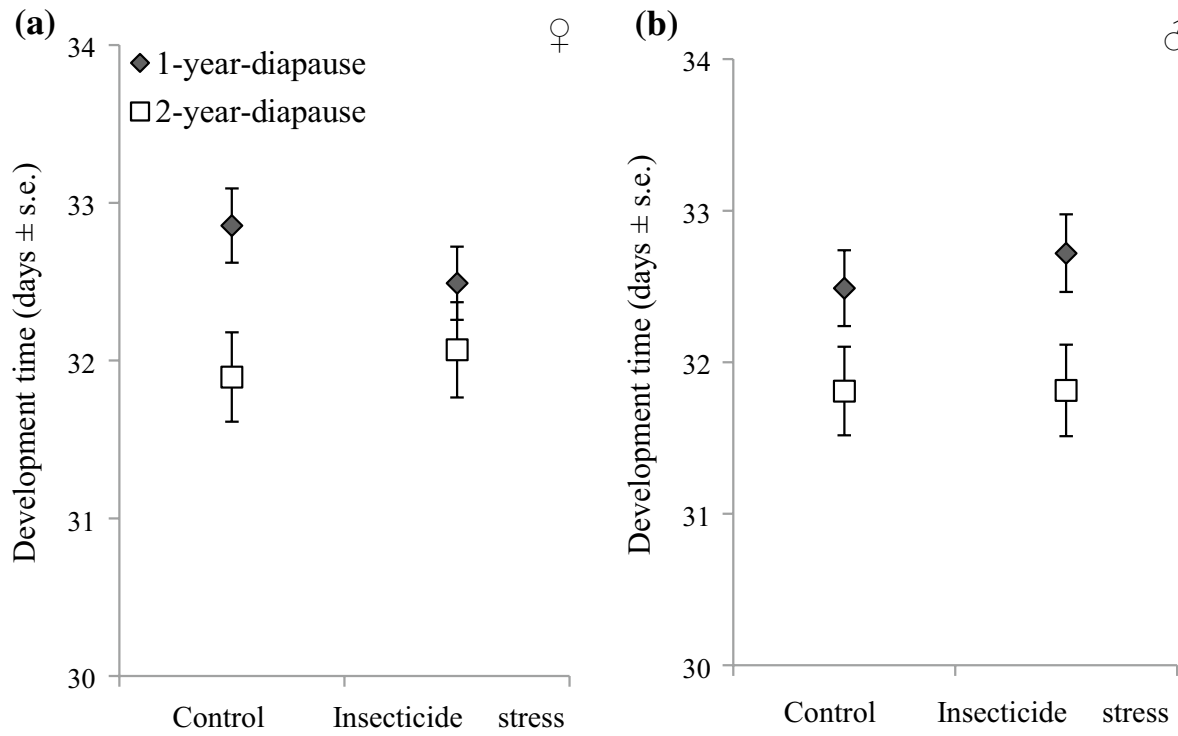

Fig. 3 Maternal diapause duration (2-year-diapause/1-year-diapause) and treatment (insecticide stress/control) effects on development time (days \pm s.e.) on $\mathbf{a}$ female and $\mathbf{b}$ male offspring. Open squares represent progeny descending from 2-year-diapause mothers and filled diamonds from 1-year-diapause mothers 


\section{Does maternal prolonged diapause affect offspring life-history traits?}

Offspring descended from the 2-year-diapause mothers had shorter development times than larvae descended from 1-year-diapause mothers $\left(\mathrm{F}_{3,603}=11.8 ; p=0.001\right.$; Fig. 3a, b). Insecticide exposure $\left(\mathrm{F}_{3,603}=0.004 ; p=0.952\right)$ or offspring sex $\left(\mathrm{F}_{3,603}=0.31\right.$; $p=0.581$ ) had no effect on the development time. The difference in the development time between the two maternal diapause groups was 0.6 days (Fig. 3a, b).

Maternal diapause duration had a significant effect on both female (ANOVA; $\left.\mathrm{F}_{2,316}=11.9 ; p=0.001\right)$ and male $\left(\mathrm{F}_{2,285}=12.5 ; p<0.001\right)$ offspring emergence body mass (Fig. 4a, b). As shown in Fig. 4, two-year-diapause mothers produced on average $6 \%(5.7 \mathrm{mg})$ bigger female and $7 \%(5.2 \mathrm{mg})$ bigger male offspring when compared to 1-year-diapause mothers. Insecticide exposure had no effect on the emergence body mass of females $\left(\mathrm{F}_{2,316}=0.02 ; p=0.884\right)$ or males $\left(\mathrm{F}_{2,285}=0.64 ; p=0.423\right)$.

\section{Does paternal prolonged diapause affect offspring life-history traits?}

In contrast to maternal prolonged diapause effects, 1-year-diapause fathers sired offspring with shorter development times when compared to offspring from 2-year-diapause fathers $\left(\mathrm{F}_{3,1120}=4.5, p=0.034\right.$; Fig. 5a, b). The difference in the development time between the two paternal diapause duration groups was 0.3 days and is shown in Fig. 5. Insecticide exposure $\left(\mathrm{F}_{3,1120}=0.046, p=0.831\right)$ had no effect on the development time but males developed faster than females $\left(\mathrm{F}_{3,1120}=4.8, p=0.029\right)$.

Two-year-diapause fathers sired both female (ANOVA; $\mathrm{F}_{2,545}=4.4, p=0.035$ ) and male $\left(\mathrm{F}_{2,564}=7.9, p=0.005\right)$ offspring with higher emergence body mass (Fig. 6a, b). Insecticide exposure had no effect on the emergence body mass in females $\left(\mathrm{F}_{2,545}=1.5\right.$,

(a)

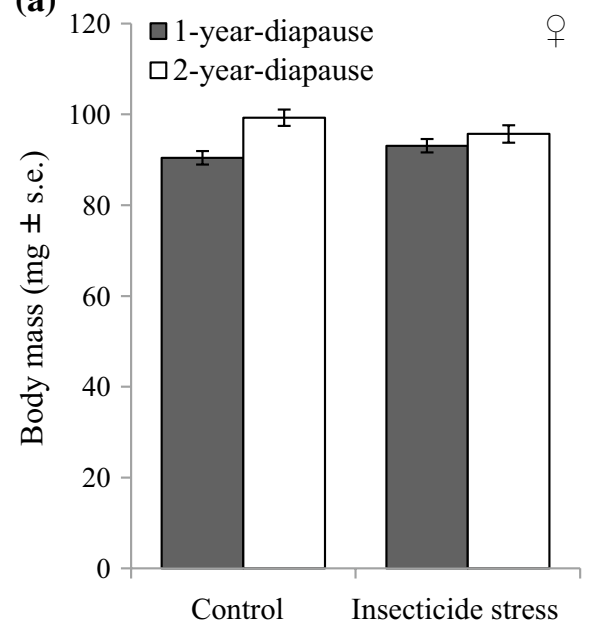

(b)

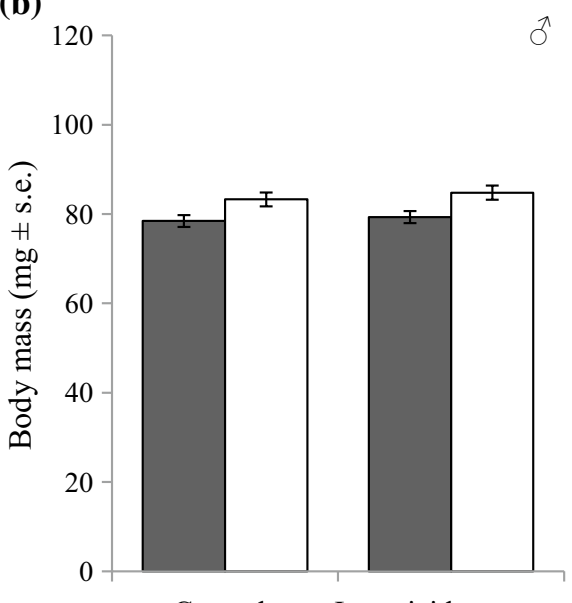

Control Insecticide stress

Fig. 4 Maternal diapause duration (2-year-diapause/1-year-diapause) and treatment (insecticide stress/control) effects on emergence body mass ( $\mathrm{mg} \pm$ s.e.) on a female and $\mathbf{b}$ male offspring. White bars represent the emerged adult body mass of progeny descending from 2-year-diapause mothers and dark bars from 1-yeardiapause mothers 

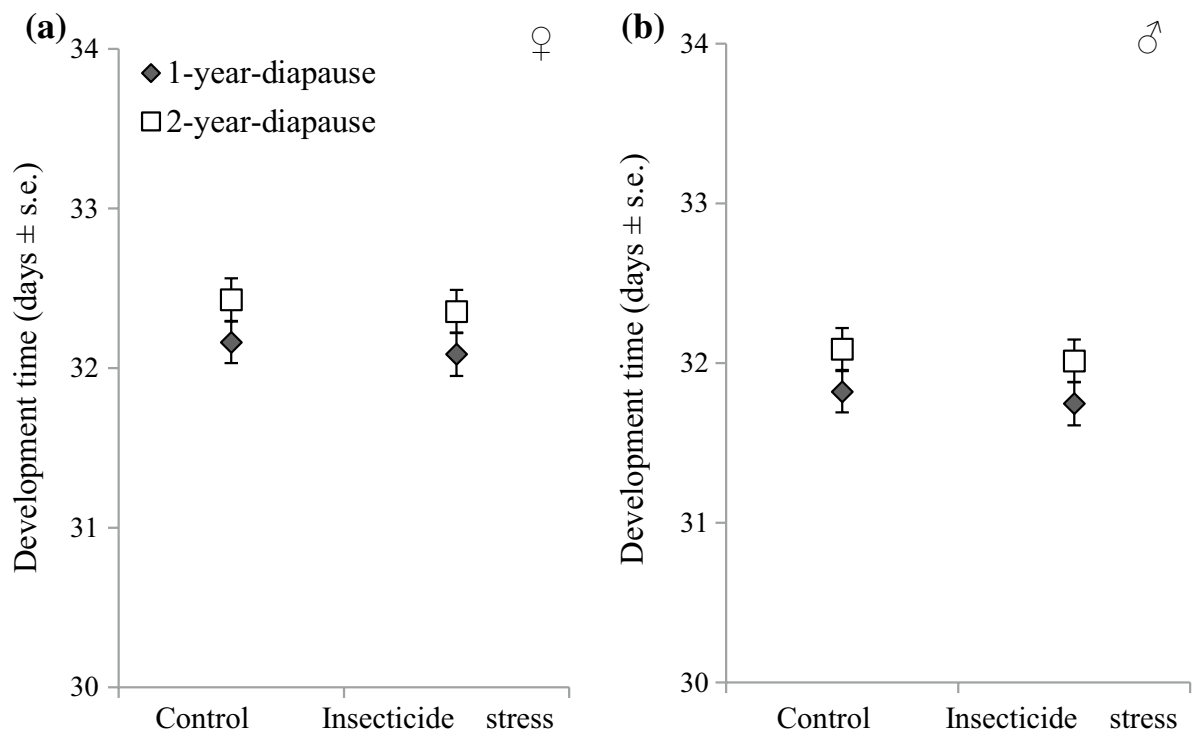

Fig. 5 Paternal diapause duration (2-year-diapause/1-year-diapause) and treatment (insecticide stress/control) effects on development time (days \pm s.e.) on $\mathbf{a}$ female and $\mathbf{b}$ male offspring. Open squares represent progeny descending from 2-year-diapause fathers and filled diamonds from 1-year-diapause fathers
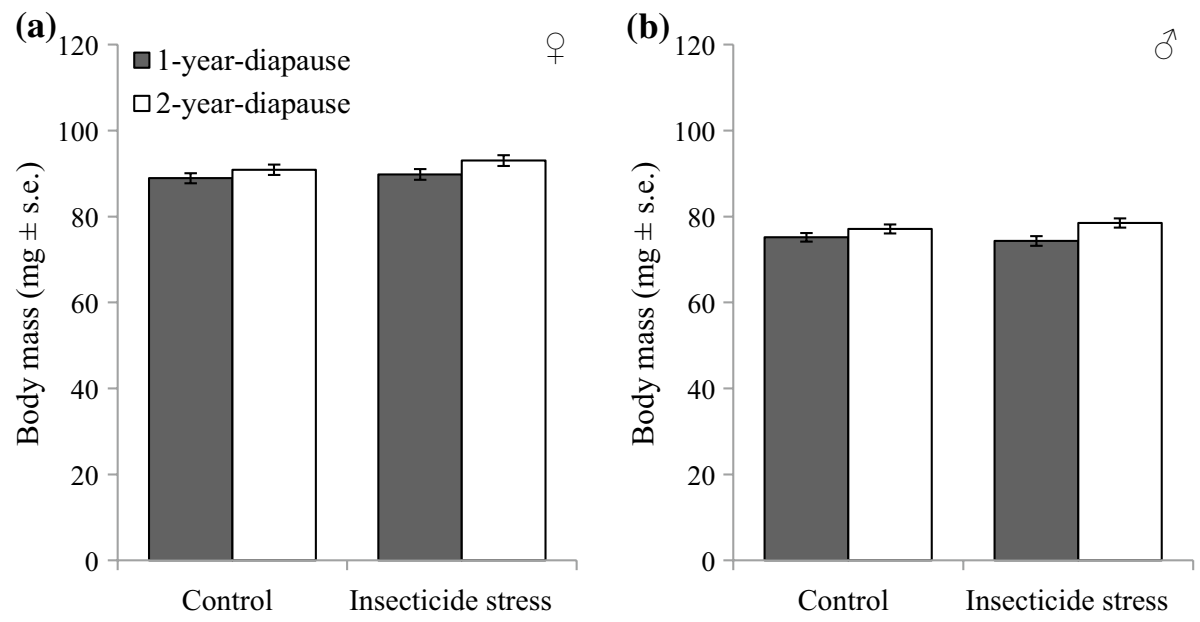

Fig. 6 Paternal diapause duration (2-year-diapause/1-year-diapause) and treatment (insecticide stress/control) effects on emergence body mass ( $\mathrm{mg} \pm$ s.e.) on $\mathbf{a}$ female and $\mathbf{b}$ male offspring. White bars represent the emerged adult body mass of progeny descending from 2-year-diapause fathers and dark bars from 1-yeardiapause fathers 
$p=0.282)$ or males $\left(\mathrm{F}_{2,564}=0.07, p=0.798\right)$. On average, 2-year-diapause fathers produce $3 \%$ (2.6 mg) bigger female offspring and $4 \%(3.1 \mathrm{mg})$ bigger male offspring when compared to 1-year-diapause fathers (Fig. 6a, b).

\section{Discussion}

Prolonged diapause has been proposed to be a risk-spreading strategy which allows individuals to skip unfavourable conditions (Menu and Debouzie 1993; Menu et al. 2000). This risk-spreading strategy, however, might not be equally beneficial to both sexes as we show that prolonged diapause had sex-specific effects on fertility, offspring quality and offspring life-history traits in the Colorado potato beetles. Prolonged diapause lowered female fertility while no effects were found for the males (Figs. 1, 2). We also found that 2-year-diapause females produced offspring with low survival (Tables 1, 2), underlying that for females this strategy can be harmful if we also account for the high mortality risk often associated with the prolonged diapause (Sims 1983). We also show that prolonged diapause had transgenerational effects as parental diapause duration affected offspring' life-history traits. These effects were mostly positive as two-yeardiapause parents produced or sired offspring with higher emergence body mass than 1-year-diapause parents (Figs. 4, 6). Higher adult body mass and size are often associated with higher overwintering survival and reproduction (Matsuo 2006; Hahn and Denlinger 2007; Piiroinen et al. 2011). In addition, 2-year-diapause mothers produced offspring with shorter development times (Fig. 3), opposite to 2-year-diapause fathers that sired offspring with longer development times when compared to 1-year-diapause fathers (Fig. 5). Although there were changes in the offspring life-history traits, the 2-year-diapause parents did not prime their offspring to have higher stress tolerance and increase their chemical insecticide stress tolerance.

Prolonged diapause had negative effects on female fertility. 2-year-diapause mothers produced fewer offspring with lower larvae-to-adult survival, but they produced offspring with shorter development time and higher body mass when compared to 1-year diapause females. Trade-off between prolonged dormancy and fecundity has been demonstrated also in European cherry fruit fly (Rhagoletis cerasi) (Moraiti et al. 2012) and many studies have reported that older mothers produce offspring with lower larvae-to-adult survival or shorter lifespan (the Lansing effect) (Hercus and Hoffmann 2000; Marshall et al. 2010; Lind et al. 2015). The negative effects of prolonged diapause could be due to a decline in general physiological condition (Hercus and Hoffmann 2000) such as lower lipid reserves (Danks 1987; Koštál 2006) or oxidative stress (Ushatinskaya 1966, 1978). Our physiological data suggest that the 2-year-diapause mothers had lower reduced to oxidized glutathione (i.e. GSH/GSSG) ratio which could mean decreased defence against free radicals, and thus increased cellular oxidative stress and/or DNA damage (Asensi et al. 1999). Increased or decreased activities of oxidative stress biomarkers could also lead to trade-offs and have negative effects on fertility. Alternatively, the negative fertility effects could stem from age effects as the prolonged diapause means increased chronological age and increased life span. It is well known that increasing age in females of Callusobruchus maculatus, Drosophila serrata and Callosobruchus chinensis decreases fertility, egg size and egg hatching (Fox 1993; Fox and Dingle 1994; Hercus and Hoffmann 2000; Yanagi and Miyatake 2002; Fox et al. 2003). Hercus and Hoffmann (2000) have also shown that age effects can be present and transferred through multiple generations, as grandmothers' age has been 
associated with the decreased egg hatching rate of their grand-offspring. Insects also build up fat body reserves to survive the diapause, sometimes also at the expense of other body tissues such as reproductive tissues. While prolonging diapause does allow females to skip unfavourable seasons it carries costs by means of lower fertility and decreased offspring survival.

Opposite to females, 2-year-diapause males sired an equal amount of offspring as 1-year-diapause males. In addition, paternal diapause duration had no effect on the larvae-to-adult survival of their offspring. A few previous studies have tried to investigate both maternal and paternal age effects and have found that ageing in males has no or small effects on fertility compared to females (Butz and Hayden 1962; Fox et al. 2003). Paternal effects have been suggested to be smaller than maternal effects because the former are mediated via maternal responses and thus females can mitigate negative paternal effects (Crean and Bonduriansky 2014). Ageing does not have such a strong effect on male fertility as on females due to the low costs of producing sperm compared to eggs (Royer and McNeil 1993). Therefore, the negative paternal effects can be mitigated by the 1-year-diapause females in our experiment. We are also aware that we might overestimate positive paternal effects since we did not include the combination of 2-year-diapause mothers and fathers. We also did not let females to choose between the males of different diapause duration. However, it has been shown in many species that females tend to prefer chronologically older males (Beck and Powell 2000; Beck et al. 2002).

The prolonged diapause carried also positive life-history effects and we found that both 2-year-diapause mothers and fathers produced or sired offspring with higher emergence body mass (Figs. 4, 6). This suggests that parents who have prolonged their diapause contribute positively to their offspring fitness and thus the low fertility in females might result from the progeny size-number trade-off (Clark et al. 2001). Alternatively, large offspring body mass could result from a differential survival during the larval period. This is unlikely as this effect is present in both parents. We also found that 2-year-diapause mothers produced offspring with shorter development times, opposite to 2-year-diapause fathers that sired offspring with longer development times when compared to 1-year-diapause parents. The differences in the development times are small. The larvae were grown in the $23{ }^{\circ} \mathrm{C}$ at the laboratory conditions without natural enemies. In nature, these differences are likely much bigger. Mixed evidence of parental age effects on the development time of the offspring have been reported before ((Halle et al. 2015) and references therein). We show that the maternal and paternal diapause duration can affect development time differently. Paternal prolonged diapause effects can be mitigated via maternal effects, which could partially explain the difference between the parental age effects on the development time of the offspring. Together these life-history results suggest that, in general, parental prolonged diapause can be advantageous for the offspring, as higher body mass has been associated with higher overall fitness, fertility, overwintering survival and mating success (Stearns 1992; Kingsolver and Huey 2008; Lehmann et al. 2012). In addition, 2-year-diapause mothers might be able to compensate for lower fertility by producing bigger offspring.

Prolonged parental diapause was not associated with increased chemical stress tolerance of offspring as suggested by the literature (Kirkwood and Austad 2000). This could be due to the fact that the Colorado potato beetle is infamous for developing resistance against different insecticides (Alyokhin et al. 2008; Mota-Sanchez and Wise 2019). It is possible that the lack of differences may be due to the population we used, which may be exceptionally resistant to organophosphate insecticides (Margus 2018). Beetle populations from the USA have been reported to have a high frequency of the organophosphate insecticide resistanceassociated (S291G) mutation (Piiroinen et al. 2013). Thus, our results may underestimate 
the effects of prolonged diapause on offspring stress-tolerance in more susceptible populations. Alternatively, stress tolerance (incl. chemical stress) that has been associated with longevity (Kirkwood and Austad 2000) might not decouple with prolonged diapause. Insecticides usually target very specific sites and it is possible that prolonged diapause does not induce changes in these sites. However, 2-year-diapause parents did also not produce offspring with decreased stress tolerance, suggesting that other prolonged diapause effects did not explain insecticide exposure results. Although, we assessed that 2-year-diapause mothers produced offspring with lower larvae-to-adult survival, this did not decrease the survival after the insecticide exposure.

\section{Conclusions}

Skipping one breeding season by prolonging diapause can carry a cost in females but not in males, which may have population-level consequences. As a result, females with prolonged diapause, and hence lower fertility and lower offspring survival, are less likely to contribute as much to population growth and dynamics as younger females with higher fertility. In turn, prolonged diapause in males carried no costs and it could be still a strategy for them to skip unfavourable environmental conditions and thus decrease the risk of the reproductive failure. Although the ability to spread the risks over multiple generations carried sexspecific fertility and fitness costs, it can be still important strategy for pest species which often live under detrimental environmental conditions, and contribute to the invasion rate (Mahdjoub and Menu 2008) and thus invasion success.

Acknowledgements Open access funding provided by University of Jyväskylä (JYU). Authors would like to thank Y. Chen (University of Vermont) for collecting the original population, M. Rainio (University of Turku) for the measuring the oxidative stress biomarkers, S. Calhim (University of Jyväskylä) for her advice for statistical analysis. We would like to thank H. Hokkanen, T. Klemola, and O. Nokelainen for their valuable comments to the manuscript. Authors would also like to thank I. Ovčarenko, A. Comellato, K. Kivisaari, E. Räsänen, J. Nevala, and E. Övermark for their help with the experiments and rearing the laboratory population. This study was done under the permission of Evira (Dnro: 8787/0614/2011 and 6049/0614/2014). This study was funded by the Finnish Academy general grant (to L.Lindström 250248 and Finnish Centre of Excellence in Biological Interactions Research 284666).

\section{Compliance with ethical standards}

Conflict of interest The authors declare no conflict of interest.

Open Access This article is licensed under a Creative Commons Attribution 4.0 International License, which permits use, sharing, adaptation, distribution and reproduction in any medium or format, as long as you give appropriate credit to the original author(s) and the source, provide a link to the Creative Commons licence, and indicate if changes were made. The images or other third party material in this article are included in the article's Creative Commons licence, unless indicated otherwise in a credit line to the material. If material is not included in the article's Creative Commons licence and your intended use is not permitted by statutory regulation or exceeds the permitted use, you will need to obtain permission directly from the copyright holder. To view a copy of this licence, visit http://creativecommons.org/licenses/by/4.0/. 


\section{References}

Alyokhin A, Baker M, Mota-Sanchez D, Dively G, Grafius E (2008) Colorado potato beetle resistance to insecticides. Am J Potato Res 85:395-413

Alyokhin A, Udalov M, Benkovskaya G (2013) The Colorado potato beetle. In Giordanengo P, Vincent P, Alyokhin A (eds.), Insect pests of potato: global perspectives on biology and management. Academic Press, Oxford, pp 11-29

Arrese EL, Soulages JL (2010) Insect fat body: energy, metabolism, and regulation. Annu Rev Entomol 55:207-225

Asensi M, Sastre J, Pallardo FV et al (1999) Ratio of reduced to oxidized glutathione as indicator of oxidative stress status and DNA damage. Methods Enzymol 299:267-276

Beck C, Powell LA (2000) Evolution of female mate choice based on male age: Are older males better mates? Evol Ecol Res 2:107-118

Beck CW, Shapiro B, Choksi S et al (2002) A genetic algorithm approach to study the evolution of female preference based on male age. Evol Ecol Res 4:275-292

Boiteau G, Le Blanc JR (1992) Colorado potato beetle: life stages. Agriculture Canada Publication 1878/E. Communications Branch, Agriculture Canada

Butz A, Hayden P (1962) The effects of age of male and female parents on the life cycle of Drosophila melanogaster. Ann Entomol Soc Am 55:617-618

Chang Y, Tauber MJ, Tauber CA (1996) Reproduction and quality of F1 offspring in Chrysoperla carnea: differential influence of quiescence, artificially-induced diapause, and natural diapause. $\mathrm{J}$ Insect Physiol 42:521-528

Chouaibou MS, Chabi J, Bingham GV et al (2012) Increase in susceptibility to insecticides with aging of wild Anopheles gambiae mosquitoes from Côte d'Ivoire. BMC Infect Dis 12:214

Clark JM, Lee SH, Kim HJ et al (2001) DNA-based genotyping techniques for the detection of point mutations associated with insecticide resistance in Colorado potato beetle Leptinotarsa decemlineata. Pest Manag Sci 57:968-974

Collatz KG, Sohal RS (1986) Insect aging. Springer, Berlin

Crean AJ, Bonduriansky R (2014) What is a paternal effect? TREE 29:554-559

Danks HV (1987) Insect dormancy: an ecological perspective. Biological Survey of Canada (Terrestrial Artropods). Natural Museum of Natural Sciences, Ottawa

Danks HV (1992) Long life cycles in insects. Can Entomol 124:167-187

Danks HV (2006) Insect adaptations to cold and changing environments. Can Entomol 138:1-23

de Kort C (1990) Thirty-five years of diapause research with the Colorado potato beetle. Entomol Exp Appl 56:1-13

De Loof A (2011) Longevity and aging in insects: is reproduction costly, cheap, beneficial or irrelevant? A critical evaluation of the "trade-off" concept. J Insect Physiol 57:1-11

de Wilde J, Hsiao TH (1981) Geographic diversity of the Colorado potato beetle and its infestation in Eurasia. In: Lashomb JH, Casagrande RA (eds) Advances in potato pest management. Hutchinson Ross Pubi. Co., Stroudsburg, pp 47-68

Ellers J, Van Alphen JJ (2002) A trade-off between diapause duration and fitness in female parasitoids. Ecol Entomol 27:279-284

Enayati AA, Ranson H, Hemingway J (2005) Insect glutathione transferases and insecticide resistance. Insect Mol Biol 14:3-8

Fox CW (1993) The influence of maternal age and mating frequency on egg size and offspring performance in Callosobruchus maculatus (Coleoptera: Bruchidae). Oecologia 96:139-146

Fox CW, Dingle H (1994) Dietary mediation of maternal age effects on offspring performance in a seed beetle (Coleoptera: Bruchidae). Funct Ecol 8:600-606

Fox CW, Bush ML, Wallin WG (2003) Maternal age affects offspring lifespan of the seed beetle, Callosobruchus maculatus. Funct Ecol 17:811-820

Hahn DA, Denlinger DL (2007) Meeting the energetic demands of insect diapause: nutrient storage and utilization. J Insect Physiol 53:760-773

Hahn DA, Denlinger DL (2011) Energetics of insect diapause. Annu Rev Entomol 56:103-121

Halle S, Nowizki A, Scharf I (2015) The consequences of parental age for development, body mass and resistance to stress in the red flour beetle. Biol J Linn Soc 115:305-314

Hand SC, Denlinger DL, Podrabsky JE et al (2016) Mechanisms of animal diapause: recent developments from nematodes, crustaceans, insects, and fish. Am J Physiol Regul Integr Comp Physiol 310:R1193-R1211

Hanski I (1988) Four kinds of extra long diapause in insects: a review of theory and observations. Ann Zool Fennici 25:37-53 
Hercus MJ, Hoffmann AA (2000) Maternal and grandmaternal age influence offspring fitness in Drosophila. Proc R Soc Lond B Biol Sci 267:2105-2110

Higaki M (2016) Prolonged diapause and seed predation by the acorn weevil, Curculio robustus, in relation to masting of the deciduous oak Quercus acutissima. Entomol Exp Appl 159:338-346

Jansson RK, Zitzman AE Jr, Lashomb JH (1989) Effects of food plant and diapause on adult survival and fecundity of Colorado potato beetle (Coleoptera: Chrysomelidae). Environ Entomol 18:291-297

Kingsolver JG, Huey RB (2008) Size, temperature, and fitness: three rules. Evol Ecol Res 10:251-268

Kirkwood TB, Austad SN (2000) Why do we age? Nature 408:233-238

Koštál V (2006) Eco-physiological phases of insect diapause. J Insect Physiol 52:113-127

Krishnan N, Kodrik A, Kludkiewicz A et al (2009) Glutathione-ascorbic acid redox cycle and thioredoxin reductase activity in the digestive tract of Leptinotarsa decemlineata (Say). Insect Biochem Mol Biol 39:180-188

Kroon A, Veenendaal R (1998) Trade-off between diapause and other life-history traits in the spider mite Tetranychus urticae. Ecol Entomol 23:298-304

Kučerová L, Kubrak OI, Bengtsson JM et al (2016) Slowed aging during reproductive dormancy is reflected in genome-wide transcriptome changes in Drosophila melanogaster. BMC Genom 17:50

Lehmann P, Lyytinen A, Sinisalo T et al (2012) Population dependent effects of photoperiod on diapause related physiological traits in an invasive beetle (Leptinotarsa decemlineata). J Insect Physiol 58:1146-1158

Lind MI, Berg EC, Alavioon G, Maklakov AA (2015) Evolution of differential maternal age effects on male and female offspring development and longevity. Funct Ecol 29:104-110

Mahdjoub T, Menu F (2008) Prolonged diapause: a trait increasing invasion speed? J Theor Biol 251:317-330

Margus A (2018) Adaptation to stressful environments: invasion success of the Colorado potato beetle (Leptinotarsa decemlineata). JYU dissertations 11

Margus A, Rainio M, Lindström L (2019) Can indirect herbicide exposure modify the response of the colorado potato beetle to an organophosphate insecticide? J Econ Entomol 112:2316-2323

Marshall DJ, Heppell SS, Munch SB et al (2010) The relationship between maternal phenotype and offspring quality: Do older mothers really produce the best offspring? Ecology 91:2862-2873

Matsuo Y (2006) Cost of prolonged diapause and its relationship to body size in a seed predator. Funct Ecol 20:300-306

Menu F, Debouzie D (1993) Coin-flipping plasticity and prolonged diapause in insects: example of the chestnut weevil Curculio elephas (Coleoptera: Curculionidae). Oecol 93:367-373

Menu F, Roebuck J, Viala M (2000) Bet-hedging diapause strategies in stochastic environments. Am Nat 155:724-734

Moraiti CA, Nakas CT, Papadopoulos NT (2012) Prolonged pupal dormancy is associated with significant fitness cost for adults of Rhagoletis cerasi (Diptera: Tephritidae). J Insect Physiol 58:1128-1135

Mota-Sanchez D, Wise JC (2019) Arthropod pesticide resistance database (APRD). https://www.pesti cideresistance.org/. Accessed May 2019

Peferoen M, Huybrechts R, De Loof A (1981) Longevity and fecundity in the Colorado potato beetle, Leptinotarsa decemlineata. Entomol Exp Appl 29:321-329

Piiroinen S, Ketola T, Lyytinen A et al (2011) Energy use, diapause behaviour and northern range expansion potential in the invasive Colorado potato beetle. Funct Ecol 25:527-536

Piiroinen S, Lindström L, Lyytinen A et al (2013) Pre-invasion history and demography shape the genetic variation in the insecticide resistance-related acetylcholinesterase 2 gene in the invasive Colorado potato beetle. BMC Evol Biol 13:1-13

Rainio MJ, Margus A, Lehmann P et al (2019) Effects of a glyphosate-based herbicide on survival and oxidative status of a non-target herbivore, the Colorado potato beetle (Leptinotarsa decemlineata). Comp Biochem Physiol C Toxicol Pharmacol 215:47-55

Royer L, McNeil JN (1993) Male investment in the European corn borer, Ostrinia nubilalis (Lepidoptera: Pyralidae): impact on female longevity and reproductive performance. Funct Ecol 7:209-215

Salman MHR, Hellrigl K, Minerbi S et al (2016) Prolonged pupal diapause drives population dynamics of the pine processionary moth (Thaumetopoea pityocampa) in an outbreak expansion area. For Ecol Manag 361:375-381

Salman MH, Bonsignore CP, Fels AA et al (2019) Winter temperature predicts prolonged diapause in pine processionary moth species across their geographic range. PeerJ 7:e6530

Sims SR (1983) Prolonged diapause and pupal survival of Papilio zelicaon Lucas (Lepidoptera: Papilionidae). J Lepid Soc 37:29-37

Stearns SC (1992) The evolution of life histories. Oxford University Press, Oxford 
Tatar M, Yin C (2001) Slow aging during insect reproductive diapause: why butterflies, grasshoppers and flies are like worms. Exp Gerontol 36:723-738

Tauber MJ, Tauber CA (2002) Prolonged dormancy in Leptinotarsa decemlineata (Coleoptera: Chrysomelidae): a ten-year field study with implications for crop rotation. Environ Entomol 31:499-504

Tauber MJ, Tauber CA, Masaki S (1986) Seasonal adaptations of insects. Oxford University Press, New York

Tauber MJ, Tauber CA, Obrycki JJ et al (1988) Voltinism and the induction of aestival diapause in the Colorado potato beetle, Leptinotarsa decemlineata (Coleoptera: Chrysomelidae). Ann Entomol Soc Am 81:748-754

Ushatinskaya RS (1966) Diversity of forms of physiological rest in insects as one of the causes of their biological progress. Ann Zool 3:19-30

Ushatinskaya RS (1978) Seasonal migration of adult Leptiontarsa decemlineata (Insecta, Coleoptera) in different types of soil and physiological variations of individuals in hibernating populations. Pedobiologia 18:120-126

Ushatinskaya RS (1984) A critical review of the superdiapause in insects. Ann Zool 21:3-30

Vuori KA, Lehtonen KK, Kanerva M et al (2015) Oxidative stress biomarkers in the copepod Limnocalanus macrurus from the northern Baltic Sea: effects of hydrographic factors and chemical contamination. Mar Ecol Prog Ser 538:131-144

Wang X, Xue F, Hua AI et al (2006) Effects of diapause duration on future reproduction in the cabbage beetle, Colaphellus bowringi: positive or negative? Physiol Entomol 31:190-196

Yanagi S, Miyatake T (2002) Effects of maternal age on reproductive traits and fitness components of the offspring in the bruchid beetle, Callosobruchus chinensis (Coleoptera: Bruchidae). Physiol Entomol 27:261-266

Yocum GD, Rinehart JP, Larson ML (2011) Monitoring diapause development in the Colorado potato beetle, Leptinotarsa decemlineata, under field conditions using molecular biomarkers. J Insect Physiol 57:645-652

Publisher's Note Springer Nature remains neutral with regard to jurisdictional claims in published maps and institutional affiliations. 